\title{
Can uterine secretion of modified histones alter blastocyst implantation, embryo nutrition, and transgenerational phenotype?
}

https://doi.org/10.1515/bmc-2018-0017

received October 18, 2018; accepted December 3, 2018.

Abstract: Extracellular histones support rodent and human embryo development in at least two ways. First, these molecules in uterine secretions protect embryos from inflammation caused by pathogens that gain access to the reproductive tract. Also, histones in uterine secretions likely support penetration of the uterine epithelium by blastocysts during embryo implantation. Extracellular histones seem to preserve amino acid transport system $\mathrm{B}^{0,+}$ in blastocysts by inhibiting its activity. Preservation of system $\mathrm{B}^{0,+}$ is needed because, at the time of invasion of the uterine epithelium by motile trophoblasts, system $\mathrm{B}^{0,+}$ is likely reactivated to help remove tryptophan from the implantation chamber. If tryptophan is not removed, T-cells proliferate and reject the implanting blastocyst. Epigenetic modification of histones could alter their promotion of normalimplantation through, say, incomplete tryptophan removal and, thus, allow partial T-cell rejection of the conceptus. Such partial rejection could impair placental development, embryonal/fetal nutrition, and weight gain prior to birth. Small-for-gestationalage offspring are predisposed to developing metabolic syndrome, obesity, and associated complications as adults. Shifting expression of these phenotypes might contribute to transgenerational variation and evolution. The spectrum of possible extracellular histone targets in early development warrant new research, especially since the effects of epigenetic histone modifications might be transgenerational.
Keywords: amino acid transport; epigenetic modification; obesity; placental function; small-for-gestational-age.

\section{Introduction}

Histones are best-known for their roles in eukaryotic chromatin structure and function [1]. However, these macromolecules also have less well-known functions outside the nucleus and even outside the cell [2]. Some of these extracellular functions promote embryo/fetal development [3].

Extracellular histones benefit embryonal/fetal development in at least two ways. First, histones in reproductive tract secretions exhibit antimicrobial actions $[4,5]$. These actions likely prevent adverse effects of infection and inflammation on reproduction such as pre-term labor and delivery [6]. More importantly to the present discussion, uterine histone secretion may influences blastocyst implantation in the mouse and probably human uterus through preservation of amino acid transport system $\mathrm{B}^{0,+}$ activity [3]. (See the proposed mechanism for the latter action of histones in the following section.) Epigenetic modification of the histones before their secretion could alter this effect on system $\mathrm{B}^{0,+}$ and, thus, blastocyst penetration of the uterine epithelium, establishment of pregnancy, embryonal/fetal nutrition, and adult phenotype [7].

\footnotetext{
*Corresponding author: Lon J. Van Winkle, Emeritus Professor, Department of Biochemistry, Midwestern University; Professor, Department of Medical Humanities, Rocky Vista University (RVU), E-mail: Ivanwinkle@rvu.edu Rebecca Ryznar: Assistant Professor of Molecular Biology, Department of Biomedical Sciences, RVU, 8401 S. Chambers Road, Parker, CO 80134, USA
} 


\section{Direct contribution of extracellular histones to early embryo development $^{\text {a }}$}

\section{Background}

Histones appear most abundantly in human uterine secretions at the time the uterus is receptive to blastocyst implantation [8]. Similarly, histones are synthesized at increased rates in the uterine epithelium and stroma of ovariectomized mice upon administration of a hormonal protocol known to result in blastocyst implantation about 25 hours later [9]. Assuming histones appear in mouse uterine fluid when the uterus becomes receptive to blastocyst implantation, what other functions might histones serve there? One good possibility involves amino acid transport system $\mathrm{B}^{0,+}$ in mouse and probably human blastocysts [7]. In order to consider this possibility in context, we will review system $\mathrm{B}^{0,+}$ involvement in early embryo development and blastocyst implantation in the uterus.

The process of blastocyst implantation in the mouse is especially amenable to study owing to experimentallycontrolled delay of implantation. While delay of implantation (diapause) occurs naturally in mice when blastocysts develop in nursing mothers, it can be produced experimentally in mice by removing their ovaries about 76 hours after their eggs have been fertilized [7, 10]. Daily administration of progesterone followed by estrogen on day seven of pregnancy then leads to blastocyst implantation 25 hours later.

During this activation of blastocysts from delay of implantation, signaling owing to leucine uptake via amino acid transport system $\mathrm{B}^{0,+}$ results specifically in development of trophoblast motility and penetration of the uterine epithelium [7]. This signaling is set in motion by increases in the $\mathrm{Na}^{+}$and $\mathrm{K}^{+}$concentrations in uterine secretions about six hours after estrogen administration to ovariectomized, progesterone-treated rodents [11, 12]. These ions drive net $\mathrm{Na}^{+}$-dependent system $\mathrm{B}^{0,+}$ leucine uptake by the blastocyst trophectoderm [7]. Leucine then stimulates mTOR signaling which results in development of trophoblast motility and penetration of the uterine epithelium about 19 hours later [7]. Subsequent to this leucine uptake and mTOR signaling, the uterine environment somehow suppresses system $\mathrm{B}^{0,+}$ activity beginning about 10 hours after estrogen administration $[10,13]$. For example, blastocysts take up a radiolabeled, nonmetabolizable amino acid in utero, when it is administered to their mothers about six hours after estrogen administration, but little or no uptake occurs when the amino acid is administered four hours before or after this time [13].

Although system $\mathrm{B}^{0,+}$ is relatively inactive in utero during the 15 hours prior to blastocyst implantation, it can be reactivated to even greater levels of transport activity simply by removing blastocysts from the uterus near the time of implantation [10]. This ability to reactivate system $\mathrm{B}^{0,+}$ activity also likely serves an important physiological function [7]. After reactivation, system $\mathrm{B}^{0,+}$ would help to selectively remove tryptophan from the implantation chamber during initial penetration of the uterus by motile trophoblasts and, thus, help to suppress T-cell proliferation and immunologic rejection of the blastocyst $[14,15]$. Without the essential amino acid, tryptophan, T-cells cannot grow.

\section{Possible role of histones}

But what reversibly suppresses system $\mathrm{B}^{0,+}$ activity beginning about 15 hours before blastocyst implantation? Good candidates include histones that are likely secreted by uterine epithelial and possibly stromal cells when the uterus becomes receptive to blastocyst attachment and penetration [9]. At near the histone concentrations detected in human and bovine uterine fluid [5, 8], we found these macromolecules to inhibit amino acid uptake by mouse blastocysts. System $\mathrm{B}^{0,+}$ activity, in particular, was inhibited much more than the activities of several other amino acid transport systems in blastocysts [16]. In fact, the extent to which histones inhibited each of four different amino acid transport systems in blastocysts, differed from each other $(\mathrm{p}<0.02)$, and ranged from near $90 \%$ inhibition of system $\mathrm{B}^{0,+}$ to no inhibition of system $\mathrm{L}$ (another amino acid transport system). Inhibition of system $\mathrm{B}^{0,+}$ activity by histones is rather specific for these cationic proteins since the same concentrations of several other basic proteins, protamine, lysozyme, and cytochrome $\mathrm{C}$, had no effect on amino acid uptake by blastocysts $[17,18]$.

Perhaps not coincidentally, the effect size of the system $\mathrm{B}^{0,+}$ inhibition by histones equals the effect size for reduction of the rate of amino acid transport into blastocysts in utero between about six and 10 hours after estrogen administration to progesterone-maintained ovariectomized mice [3, 13]. In addition, histone $\mathrm{H} 2 \mathrm{~A}$ (one of the more conspicuous histones in secretions of the receptive human uterus; [8]) is likely more effective at inhibiting amino acid uptake by blastocysts than other 
histones [19]. Reactivation of system $\mathrm{B}^{0,+}$ in blastocysts, at the time of blastocyst penetration of the uterine epithelium, could be accomplished simply by removing histones from the relatively small amount of uterine fluid in implantation chambers. In this regard, proteases, likely needed to hydrolyze histones to products unable to inhibit system $\mathrm{B}^{0,+}$, appear to abound in these chambers [20].

As expected from the present discussion, injection of histone solutions into the uterine lumen six hours before implantation had no obvious effect on further blastocyst development [17]. In contrast, similar injection of other substances that inhibit amino acid uptake by blastocysts, such as basic pancreatic trypsin inhibitor [18], prevented implantation of most blastocysts [21]. While other interpretations are possible, these results are consistent with the current argument that histones are physiological inhibitors of system $\mathrm{B}^{0,+}$ in blastocysts in utero.

While it is unclear why system $\mathrm{B}^{0,+}$ activity needs to be suppressed after mTOR signaling, we observed one tantalizing possibility. When we incubated delayedimplantation blastocysts for 25 hours in vitro in medium containing a relatively high $\mathrm{Na}^{+}$concentration, they irreversibly lost their $\mathrm{Na}^{+}$-dependent component of amino acid uptake [22]. This apparent loss of $\mathrm{Na}^{+}$-dependent system $\mathrm{B}^{0,+}$ activity would likely mean that the ability of blastocysts to activate net $\mathrm{Na}^{+}$-dependent tryptophan uptake would also be lost. If such loss were to occur in the implantation chamber in utero, then implanting blastocysts could face immunological rejection owing to tryptophan availability to T-cells [14, 15]. Hence, suppression of system $\mathrm{B}^{0,+}$ activity in blastocysts by histones after initiation of mTOR signaling could preserve this system for activation and concentration of tryptophan into trophoblast cells at the time trophoblasts penetrate the uterine epithelium.

\section{Why is system $B^{0,+}$ knockout not lethal?}

Knockout of the gene encoding the $\mathrm{B}^{0,+}$ transport protein in mice is not lethal nor does it prevent reproduction [23]. Hence, one could argue that system $\mathrm{B}^{0,+}$ tryptophan uptake in the implantation chamber and leucine uptake to activate mTOR are not needed for development of trophoblast motility and penetration of the uterine epithelium by blastocysts. When system $\mathrm{B}^{0,+}$ is expressed in mouse embryos, however, transport of leucine specifically by this system (and not other systems) is essential to development of trophoblast motility in blastocysts [24]. Clearly, when system $\mathrm{B}^{0,+}$ is expressed, it has multiple phenotypes, in addition to giving rise to trophoblast motility [7, 24], such as normal weight/obesity [25], male fertility/infertility [26], modification of cystic fibrosis phenotype [27], and breast cancer tumor promotion [23].

Furthermore, the polyamines, putrescine, spermidine and spermine, overcome rapamycin inhibition of mTOR and the resultant block of trophoblast motility in mouse blastocysts, probably as signaling molecules downstream to mTOR [7]. In porcine trophoblast cells, the polyamine, putrescine, stimulates protein synthesis by activating mTOR [28], and pig blastocysts do not exhibit system $\mathrm{B}^{0,+}$ activity [29]. Such possible compensatory mechanisms must substitute for system $\mathrm{B}^{0,+}$ when it is not expressed in mouse blastocysts to foster development of trophoblast motility and penetration of the uterine epithelium.

\section{Epigenetic histone modification before secretion in uterine fluid could alter blastocyst implantation and development through adulthood}

\section{How might the role of system $B^{0,+}$ in establishing pregnancy influence development and health across the life cycle?}

Some alleles of the X-linked SLC6A14 genes, that encode system $\mathrm{B}^{0,+}$ amino acid transport proteins $\left(\mathrm{ATB}^{0,+} \mathrm{s}\right)$, foster human and likely mouse obesity $[7,25,30,31]$. ATB $^{0,+} \mathrm{s}$ are expressed predominantly in eye, colon, and lung of adults, however [32, 33], so it seems unlikely that different forms of $\mathrm{ATB}^{0,+} \mathrm{s}$ in these tissues cause metabolic syndrome and obesity. The role of system $\mathrm{B}^{0,+}$ in establishing pregnancy and embryo nutrition likely relates better to the mechanisms by which different system $\mathrm{B}^{0,+}$ activities in blastocysts could, in some cases, foster adult obesity [7].

For example, $\mathrm{ATB}^{0,+} \mathrm{s}$ with lower activity might incompletely suppress T-cell proliferation through tryptophan deprivation. Such partial T-cell rejection could impair placental formation and function, embryo nutrition, and the resultant growth and development of the fetuses. We observed variable and sometimes relatively low capacities to activate system $\mathrm{B}^{0,+}$ in implanting blastocysts [10]. This low system $\mathrm{B}^{0,+}$ activity could allow tryptophan to promote some T-cell proliferation to partially reject conceptuses and, thus, impair placental formation and function. Impaired placental transport of 
nutrients to embryos and fetuses leads to development of small-for-gestational-age offspring that exhibit metabolic syndrome and obesity as adults [34].

\section{Epigenetic histone modification might also alter system $\mathrm{B}^{0,+}$ activity during blastocyst penetration of the uterine epithelium.}

If the histones secreted by the uterus have altered structure owing to epigenetic modification, they could influence blastocyst implantation and placental formation. Such an influence on the resultant embryo nutrition might lead to development of small-for-gestational-age offspring with predispositions for metabolic syndrome and obesity [34].

For example, modified histone structure could conceivably resist proteolytic or other means of histone inactivation in the blastocyst implantation chamber [35]. This change would increase histone inhibition of system $\mathrm{B}^{0,+}$ while blastocysts penetrate the uterine epithelium. The ability of system $\mathrm{B}^{0,+}$ to help remove tryptophan would, thus, be impaired possibly leading to partial T-cell rejection of the conceptus and impaired placental formation. A resultant decrease in the ability of the placenta to provide nutrients to the embryo and fetus would likely lead to delivery of small-for-gestational-age offspring.

Such effects of excess tryptophan on pregnancy have, in fact, been observed. Pregnant mice fed a diet supplemented with 5\% tryptophan had increased concentrations of tryptophan in blood, liver, fetuses, and placentas [36]. A diet supplemented with $2 \%$ tryptophan had no effect on tryptophan levels in mice, so mice adapted to prevent tryptophan accumulation in organs during $2 \%$ tryptophan supplementation. Since 5\% tryptophan supplementation began before their pregnancies, these mice also likely had greatly increased tryptophan concentrations in their implantation chambers at the time blastocysts began to penetrate their uterine epithelia. In this scenario, the excess tryptophan likely overwhelmed the capacity of system $\mathrm{B}^{0,+}$ to help remove it from the implantation chamber. Subsequent partial T-cell rejection of the conceptus then could have impaired placental formation and its ability to supply nutrients to the embryo and fetus. Consistent with this interpretation, mice consuming the $5 \%$ tryptophan diet gave birth to small-for-gestational-age offspring [36]. Placentas from these mice also were reduced in size and had structural abnormalities.

In a similar study, we found diets supplemented with about $2 \%$ isoleucine during the first half of pregnancy in mice, led to loss of the important positive correlation between fetal and placental weights [37]. Low placental weight is associated with small-for-gestational offspring in malnourished women [38]. In our study, dietary isoleucine was intended to inhibit leucine and tryptophan transport via system $\mathrm{B}^{0,+}$ during the peri-implantation period in mice and, thus, alter subsequent placental formation and function, embryonal/fetal nutrition, and newborn development. Offspring of mice consuming $2 \%$ isoleucine did, indeed, appear to be small-for-gestational age [37]. While growth of the pups from these pregnancies, and those after tryptophan supplementation, were not followed into older adulthood, other studies show they were predisposed to develop metabolic syndrome, type 2 diabetes mellitus, coronary heart disease, and hypertension [34]. Owing to the possible importance of histones and their modification in regulating system $\mathrm{B}^{0,+}$ tryptophan transport during blastocystimplantation, what other possible functions might intra- and extracellular histones serve in embryo development?

\section{Epigenetic histone modification could contribute to transgenerational variation and evolution}

\section{Direct effects on gene expression}

The Developmental origins of health and disease hypothesis posits that factors contributing to maternal lifestyle such as exposure to toxins and diet can result in changes to the early embryo that can cause both genetic and epigenetic changes that may last a lifetime [39]. If the environmental exposure influences more permanent epigenetic modifications in the sex cells or very early embryo, it will result in transgenerational transmission of traits even in the absence of further environmental exposure of subsequent generations. It is thought that during early embryo development, the epigenetic reprogramming window is a critical period for environmental factors to cause permanent changes in epigenetic variations and result in disease susceptibility [40].

Thus, preimplantation embryos may be altered through epigenetic regulation and changes in gene expression due to unhealthy maternal conditions such as poor diet, high stress, or toxin exposures [39, 40]. These changes could in turn produce lasting effects on offspring and future generations. In humans, life-style can foster obesity, in part, through epigenetic histone modifications 
that might persist for generations [41]. For example, altered gene expression owing to epigenetic histone modification in nematodes grown at 25 degrees Celsius continues for up to 14 generations after returning the worms to 20 degrees Celsius [42]. Such epigenetic changes in human histone structure likely alter gene expression and cause several metabolic disorders [31, 43]. Many of these epigenetic histone modifications likely arise during development of preimplantation embryos. For example, it has been shown that histone deposition dynamics during the preimplantation period are critical for normal development. Specifically, histones H2A [44] and H3 [45] variants are important for epigenetic chromatin remodeling after egg fertilization in mice.

Disturbance in the amount or nature of modified histones in the uterine fluid of preimplantation embryos may contribute to further epigenetic changes in gene expression that persist in offspring and future generations. Little is known about the effects of extracellular histones on gene expression in the early embryo. In other cells, however, histones cross the plasma membrane readily, enter the nucleus, become associated with chromatin, and affect transcription [46]. In the latter study, histones H2A and $\mathrm{H} 4$ were most effective at entering cells through the plasma membrane, whereas $\mathrm{H} 2 \mathrm{~B}$ and $\mathrm{H} 3$ exhibited lower levels of translocation. Changes in the amounts or types of modified histones in uterine fluid may directly affect transcription in the early embryo, which could produce long-lasting effects on the offspring. Interestingly, more immediate effects of dysregulated histone H2B production and secretion into amniotic fluid may include pre-term births in humans [47].

In particular, maternal nutritional stress has been shown to alter the epigenome of offspring and subsequent generations in humans and animal systems [48]. Famine or improper nutrition during the preimplantation period can change blastocyst developmental potential and result in postnatal hypertension, metabolic abnormalities, and even mental health disorders [49]. Interestingly, children born via in vitro fertilization, and without fully normal uterine fluid and extracellular histone exposure, have been found to have different epigenetic profiles and are more susceptible to developing phenotypes resembling those of children born following maternal nutritional stress [50]. Uterine fluid during the preimplantation period is very sensitive to the maternal environment [50] so, theoretically, changes in diet could impact production and action of extracellular histones during this critical developmental window. Resultant epigenetic changes in genes and histones in early embryos could persist for generations.

\section{Extracellular histone action and phenotypic variation}

Similarly, epigenetic histone modification owing to life-style might influence their extracellular actions. Such structural changes in extracellular histones could also persist for generations if they first appear in early embryos. It has been shown that extracellular histones may contribute to early embryo development by inhibiting amino acid transport systems, but what are other possible extracellular targets? While other possible direct effects of extracellular histones in early development are yet to be studied, extracellular histones are known to have beneficial actions elsewhere.

For example, neutrophil extracellular traps (NETs) require histones to function. NETS form during NETosis, a process of programed neutrophil death. These netlike structures are composed of cytosolic proteins and decondensed chromatin. NETs trap and kill bacterial, fungal, viral, and other parasitic infections [51].

Free histones also act to inactivate microbes [52]. For example, amniotic fluid contains free histones that help to limit bacterial action by neutralizing their lipopolysaccharide (LPS) [4]. Otherwise, LPS can cause premature labor and delivery of small-for-gestational-age offspring [6].

Interestingly, extracellular histones have also been shown to act as carriers of various biomolecules across plasma membranes and have even been described as potential novel mediators for future gene delivery systems. More specifically, histones were found to mediate the translocation of biomolecule-histone conjugates such as BSA and nucleic acids attached to histones [46]. Such extracellular histone actions further expands the ways these molecules might contribute to epigenetic variation in early development.

In addition, the composition of uterine fluid is highly sensitive to the maternal environment during the preimplantation period. For example, a low protein diet has been shown to alter the concentrations and proportions of amino acids in blood and uterine fluid. Such effects could influence uterine production and secretion of histones during early development. If these changes in uterine fluid histones result in epigenetic histone modification in early embryos, then modified intra- and extracellular histone structure could become more permanent $[53,54]$. That is, intracellular epigenetic histone modifications could continue in subsequent generations, and the modified histones would also be secreted and have extracellular actions. 


\section{Conclusions}

Extracellular histones appear to contribute to early embryo development by inhibiting amino acid transport system $\mathrm{B}^{0,+}$ in blastocysts as they approach implantation in the uterus. Reactivation of system $\mathrm{B}^{0,+}$ to help remove tryptophan from the implantation chamber is needed, however, to prevent T-cell proliferation and rejection of the embryo as its trophoblast cells penetrate the uterine epithelium. Hence, histones likely need to be removed or inactivated in the implantation chamber to allow system $\mathrm{B}^{0,+}$ to become more active.

Epigenetic structural changes in histones that preserve or prolong histone inhibition of system $\mathrm{B}^{0,+}$ could, thus, allow tryptophan to accumulate and T-cells partially to reject the implanting blastocyst. Such a process could impair placental formation and embryonal/fetal nutrition. Resultant small-for-gestational-age offspring are predisposed to develop metabolic syndrome, obesity, and related health problems as adults. Shifting expression of these phenotypes, owing to variations in secreted histone structure, might contribute to transgenerational variation and evolution. The spectrum of possible intra- and extracellular targets of epigenetically modified histones in early development awaits full exploration especially because their effects may be transgenerational.

Footnote: ${ }^{a}$ Portions of this section are excerpts from Van Winkle, 2017 [3] with permission of the copyright holder.

Acknowledgement: We thank Dr. Philip Iannaccone for useful discussions and a critique of an earlier draft of the manuscript.

Conflict of interest: The authors state no conflict of interest.

\section{References}

1. Harr JC, Gonzalez-Sandoval A, Gasser SM. Histones and histone modifications in perinuclear chromatin anchoring: from yeast to man. EMBO Reports. 2016;17(2):139-55.

2. Parseghian MH, Luhrs KA. Beyond the walls of the nucleus: the role of histones in cellular signaling and innate immunity. Biochemistry and Cell Biology. 2006;84(4):589-95.

3. Van Winkle LJ. Uterine Histone Secretion Likely Fosters Early Embryo Development So Efforts to Mitigate Histone Cytotoxicity Should Be Cautious. Frontiers in Cell and Developmental Biology. 2017;5:100.

4. Witkin SS, Linhares IM, Bongiovanni AM, Herway C, Skupski D. Unique alterations in infection-induced immune activation during pregnancy. BJOG: An International Journal of Obstetrics \& Gynaecology. 2011;118(2):145-53.

5. Dráb T, Kračmerová J, Hanzlíková E, Černá T, Litváková R, Pohlová A, Tichá M, Přikryl P, Liberda J. The antimicrobial action of histones in the reproductive tract of cow. Biochemical and Biophysical Research Communications. 2014;443(3):987-90.

6. Hirsch E, Filipovich Y, Mahendroo M. Signaling via the type I IL-1 and TNF receptors is necessary for bacterially induced preterm labor in a murine model. American Journal of Obstetrics and Gynecology. 2006;194(5):1334-40.

7. Van Winkle LJ, Tesch JK, Shah A, Campione AL. System $B^{0,+}$ amino acid transport regulates the penetration stage of blastocyst implantation with possible long-term developmental consequences through adulthood. Human Reproduction Update. 2006;12(2):145-57.

8. Beier HM, Beier-Hellwig K. Molecular and cellular aspects of endometrial receptivity. Human Reproduction Update. 1998;4(5):448-58.

9. Smith JA, Martin L, King RJ, Vertes M. Effects of oestradiol-17 and progesterone on total and nuclear-protein synthesis in epithelial and stromal tissues of the mouse uterus, and of progesterone on the ability of these tissues to bind oestradiol17ß. Biochemical Journal. 1970;119(4):773-84.

10. Van Winkle LJ, Campione AL. Development of amino acid transport system $\mathrm{B}^{0,+}$ in mouse blastocysts. Biochimica et Biophysica Acta (BBA)-General Subjects. 1987;925(2):164-74.

11. Van Winkle LJ, Campione AL, Webster DP. Sodium ion concentrations in uterine flushings from "implanting" and “delayed implanting” mice. Journal of Experimental Zoology. 1983;226(2):321-4

12. Nilsson BO, Ljung L. X-ray micro analyses of cations ( $\mathrm{Na}, \mathrm{K}, \mathrm{Ca})$ and anions $(\mathrm{S}, \mathrm{P}, \mathrm{Cl})$ in uterine secretions during blastocyst implantation in the rat. Journal of Experimental Zoology. 1985;234(3):415-21.

13. Lindqvist I, Einarsson B, Nilsson O, Ronquist G. The in vivo transport of $14 \mathrm{C}-\alpha$-aminoisobuturic acid into mouse blastocysts during activation for implantation. Acta Physiologica Scandinavica. 1978;102(4):477-83.

14. Munn DH, Zhou M, Attwood JT, Bondarev I, Conway SJ, Marshall B, Brown C, Mellor AL. Prevention of allogeneic fetal rejection by tryptophan catabolism. Science. 1998;281(5380):1191-3.

15. Baban B, Chandler P, McCool D, Marshall B, Munn DH, Mellor AL. Indoleamine 2, 3-dioxygenase expression is restricted to fetal trophoblast giant cells during murine gestation and is maternal genome specific. Journal of Reproductive Immunology. 2004;61(2):67-77.

16. Van Winkle LJ. Endogenous amino acid transport systems and expression of mammalian amino acid transport proteins in Xenopus oocytes. Biochimica et Biophysica Acta (BBA)-Reviews on Biomembranes. 1993;1154(2):157-72.

17. Van Winkle LJ. Factors affecting net incorporation of radiolabeled amino acids into protein of normal and diapausing mouse blastocysts. Ph.D. Dissertation. 1975. Wayne State University, Detroit, Michigan.

18. Van Winkle, LJ, Dabich D, Andary TJ. Effects of proteinase inhibitors on amino acid incorporation in preimplantation mouse blastocysts. Fed Proc. 1973;32:214A.

19. Doman DR, Van Winkle LJ. A histone induced diminution of ${ }^{14} \mathrm{C}$ amino acid uptake and incorporation in preimplantation mouse embryos. BIOS. 1979;1:67-73. 
20. Afonso S, Romagnano L, Babiarz B. The expression and function of cystatin $C$ and cathepsin B and cathepsin L during mouse embryo implantation and placentation. Development. 1997;124(17):3415-25.

21. Dabich D, Andary TJ. Prevention of blastocyst implantation in mice with proteinase inhibitors. Fertility and Sterility. 1974;25(11):954-7.

22. Van Winkle LJ. Low $\mathrm{Na}^{+}$concentration: a factor contributing to diminished uptake and incorporation of amino acids by diapausing mouse blastocysts?. Journal of Experimental Zoology. 1977;202(2):275-81

23. Babu E, Bhutia YD, Ramachandran S, Gnanaprakasam JP, Prasad PD, Thangaraju M, Ganapathy V. Deletion of the amino acid transporter Slc6a14 suppresses tumour growth in spontaneous mouse models of breast cancer. Biochemical Journal. 2015;469(1):17-23.

24. González IM, Martin PM, Burdsal C, Sloan JL, Mager S, Harris T, Sutherland AE. Leucine and arginine regulate trophoblast motility through mTOR-dependent and independent pathways in the preimplantation mouse embryo. Developmental Biology. 2012;361(2):286-300.

25. Durand E, Boutin P, Meyre D, Charles MA, Clement K, Dina C, Froguel $P$. Polymorphisms in the amino acid transporter solute carrier family 6 (neurotransmitter transporter) member 14 gene contribute to polygenic obesity in French Caucasians. Diabetes. 2004;53(9):2483-6.

26. Noveski P, Mircevska M, Plaseski T, Peterlin B, PlaseskaKaranfilska D. Study of three single nucleotide polymorphisms in the SLC6A14 gene in association with male infertility. Balkan Journal of Medical Genetics. 2014;17(2):61-6.

27. Corvol H, Blackman SM, Boëlle PY, Gallins PJ, Pace RG, Stonebraker JR, Accurso FJ, Clement A, Collaco JM, Dang H, Dang AT. Genome-wide association meta-analysis identifies five modifier loci of lung disease severity in cystic fibrosis. Nature communications. 2015;6:8382.

28. Kong X, Wang X, Yin Y, Li X, Gao H, Bazer FW, Wu G. Putrescine stimulates the mTOR signaling pathway and protein synthesis in porcine trophectoderm cells. Biology of Reproduction. 2014;91(5):Article 106.

29. Prather RS, Peters MS, Van Winkle LJ. Alanine and leucine transport in unfertilized pig oocytes and early blastocysts. Molecular Reproduction and Development. 1993;34(3):250-4.

30. Suviolahti E, Oksanen LJ, Öhman M, Cantor RM, Ridderstråle M, Tuomi T, Kaprio J, Rissanen A, Mustajoki P, Jousilahti $P$, Vartiainen $E$. The SLC6A14 gene shows evidence of association with obesity. The Journal of Clinical Investigation. 2003;112(11):1762-72.

31. Singh RK, Kumar P, Mahalingam K. Molecular genetics of human obesity: a comprehensive review. Comptes Rendus Biologies. 2017;340(2):87-108.

32. Sloan JL, Grubb BR, Mager S. Expression of the amino acid transporter $\mathrm{ATB}^{0+}$ in lung: possible role in luminal protein removal. American Journal of Physiology-Lung Cellular and Molecular Physiology. 2003;284(1):L39-49.

33. Hatanaka T, Haramura M, Fei YJ, Miyauchi S, Bridges CC, Ganapathy PS, Smith SB, Ganapathy V, Ganapathy ME. Transport of amino acid-based prodrugs by the $\mathrm{Na}^{+}$and $\mathrm{Cl}^{-}$-coupled amino acid transporter $\mathrm{ATB}^{0,+}$ and expression of the transporter in tissues amenable for drug delivery.
Journal of Pharmacology and Experimental Therapeutics. 2004;308(3):1138-47.

34. Levy-Marchal C, Jaquet D, Czernichow P. Long-term metabolic consequences of being born small for gestational age. Pediatric Diabetes. 2004;5(3):147-53.

35. Kim K, Punj V, Kim JM, Lee S, Ulmer TS, Lu W, Rice JC, An W. MMP-9 facilitates selective proteolysis of the histone $\mathrm{H} 3$ tail at genes necessary for proficient osteoclastogenesis. Genes \& Development. 2016;30:1-12.

36. Tsuji A, Nakata C, Sano M, Fukuwatari T, Shibata K. L-tryptophan metabolism in pregnant mice fed a high L-tryptophan diet and the effect on maternal, placental, and fetal growth. International Journal of Tryptophan Research. 2013;6:21-33.

37. To CY, Campione A, Cordero K, Van Winkle LJ. Does Suboptimal Activation of System B0,+ Activity Influence Placentation and Long-Term Development Through Adulthood in Mice? Journal of the American Osteopathic Association. 2007:107(8), 349-350.

38. Gernand AD, Christian P, Paul RR, Shaikh S, Labrique AB, Schulze KJ, Shamim AA, West Jr KP. Maternal Weight and Body Composition during Pregnancy Are Associated with Placental and Birth Weight in Rural Bangladesh, 2. The Journal of Nutrition. 2012;142(11):2010-6.

39. Heindel JJ, Vandenberg LN. Developmental Origins of Health and Disease: A Paradigm for Understanding Disease Etiology and Prevention. Current Opinion in Pediatrics. 2015;27(2):248253.

40. Canovas S, Ross PJ. Epigenetics in preimplantation mammalian development. Theriogenology. 2016;86(1):69-79.

41. Dolinoy DC, Jirtle RL. Environmental epigenomics in human health and disease. Environmental and Molecular Mutagenesis. 2008;49(1):4-8.

42. Klosin A, Casas E, Hidalgo-Carcedo C, Vavouri T, Lehner B. Transgenerational transmission of environmental information in C. elegans. Science. 2017;356(6335):320-3.

43. Ordovas JM, Shen J. Gene-environment interactions and susceptibility to metabolic syndrome and other chronic diseases. Journal of Periodontology. 2008;79:1508-13.

44. Nashun B, Yukawa M, Liu H, Akiyama T, Aoki F. Changes in the nuclear deposition of histone $\mathrm{H} 2 \mathrm{~A}$ variants during pre-implantation development in mice. Development. 2010;137:3785-94

45. Akiyama T, Suzuki 0, Matsuda J, Aoki F. Dynamic replacement of histone $\mathrm{H} 3$

variants reprograms epigenetic marks in early mouse embryos. PLoS Genetics. 2011;7(10).

46. Hariton-Gazal E, Rosenbluh J, Graessmann A, Gilon C, Loyter A. Direct translocation of histone molecules across cell membranes. Journal of Cell Science. 2003;116:4577-4586.

47. Herway C, Kanninen T, Witkin SS, Saade G, Fortunato SJ, Menon R. Ethnic disparity in amniotic fluid levels of hyaluronan, histone $\mathrm{H} 2 \mathrm{~B}$ and superoxide dismutase in spontaneous preterm birth. Journal of perinatal medicine. 2013;41(3):277-82.

48. Thorsell A, Nätt D. Maternal stress and diet may influence affective behavior and stress-response in offspring via epigenetic regulation of central peptidergic function. Environmental Epigenetics. 2016;2(3).

49. Brenseke B, Prater MR, Bahamonde J, Gutierrez JC. Current thoughts on maternal nutrition and fetal programming of the metabolic syndrome. Journal of Pregnancy. 2013;2013. 
50. Feuer S, Rinaudo P. Preimplantation stress and development. Birth Defects Research Part C: Embryo Today: Reviews. 2012;96(4):299-314.

51. Papayannopoulos V. Neutrophil extracellular traps in immunity and disease. Nature Reviews Immunology. 2018;18(2):134.

52. Kawasaki H, Iwamuro S. Potential roles of histones in host defense as antimicrobial agents. Infectious Disorders-Drug Targets. 2008;8(3):195-205.

53. Eckert JJ, Porter R, Watkins AJ, Burt E, Brooks S, Leese HJ, Humpherson PG, Cameron IT, Fleming TP. Metabolic induction and early responses of mouse blastocyst developmental programming following maternal low protein diet affecting lifelong health. PLoS One. 2012;7(12):e52791.
54. Sun C, Denisenko O, Sheth B, Cox A, Lucas ES, Smyth NR, Fleming TP. Epigenetic regulation of histone modifications and Gata6 gene expression induced by maternal diet in mouse embryoid bodies in a model of developmental programming. BMC Developmental Biology. 2015 ;15(1):3. 